SHORT REPORT

\title{
Expression of connective tissue growth factor (CCN2) in desmoplastic small round cell tumour
}

\author{
A W Rachfal, M H Luquette, D R Brigstock
}

J Clin Pathol 2004;57:422-425. doi: 10.1136/jcp.2003.012344

\begin{abstract}
Background: Desmoplastic small round cell tumour (DSRCT) is a rare and often fatal abdominal tumour that is distinguished by well defined islands of cells, surrounded by prominent desmoplastic stroma. As in certain other tumours, the function of the Wilms's tumour protein (WT1) in repressing gene transcription is lost in DSRCT.

Aims: To assess the expression and localisation of connective tissue growth factor (CCN2) in DSRCT because this protein is transcriptionally repressed by WT1 and is associated with the production of abundant extracellular matrix.

Methods: CCN2 was assessed by in situ hybridisation and immunohistochemistry.

Results: CCN2 mRNA and protein were colocalised to the tumour cells themselves, in addition to stromal fibroblasts and vascular endothelial cells.

Conclusions: These data show that CCN2 is produced in high amounts by several cell types in DSRCT, and highlight a potential role for this factor in the autocrine and paracrine regulation of tumour cell growth, matrigenesis, and angiogenesis.
\end{abstract}

$\mathrm{D}$ esmoplastic small round cell tumour (DSRCT) is a rare aggressive tumour that predominantly affects young male patients. DSRCT occurs on the peritoneal surfaces of the abdomen and is characterised by well defined islands of small cells, surrounded by prominent desmoplastic stroma. DSRCT has a very poor prognosis and, despite surgery, radiotherapy, and chemotherapy, patients typically die within several months to a few years after diagnosis. ${ }^{1}$ DSRCT is associated with a recurrent chromosomal translocation, $\mathrm{t}(11 ; 22)(\mathrm{pl3} ; \mathrm{q} 12)$, which fuses the $\mathrm{N}$-terminus of the Ewing sarcoma (EWS) gene to the C-terminus of the Wilms's tumour (WT1) gene, and causes a loss of the typical repressive function of WTl on gene transcription. ${ }^{2}$ The EWSWT1 fusion encodes a novel transcription factor comprising a strong EWS transcriptional activation domain merged with a WT1 DNA binding domain. This fusion creates an oncogenic chimaera, which may lead to loss of the tumour suppresser effects of the WTl gene, in addition to an increase in the EWS driven expression of growth factors usually repressed by WT1. ${ }^{34}$

\begin{abstract}
"Desmoplastic small round cell tumour is associated with a recurrent chromosomal translocation, $t(11 ; 22)(p 13 ; q 12)$, which fuses the $\mathrm{N}$-terminus of the EWS gene to the C-terminus of the WT1 gene, and causes a loss of the typical repressive function of WT1 on gene transcription"
\end{abstract}

WTl represses activators that stimulate initiation and/or elongation steps in RNA polymerase II transcription. ${ }^{5}$ In addition, through a cis acting epidermal growth factor receptor (EGRl) binding site in their promoters, the transcription of insulin-like growth factor II (IGF-II), platelet derived growth factor $\alpha$ chain (PDGF- $\alpha$ ), and transforming growth factor $\beta$ (TGF $\beta$ ) are repressed by WTl. ${ }^{3}$ WTl may also play an important role in regulating TGF $\beta$ expression and indirectly controlling extracellular matrix production. ${ }^{3}$ These same genes, in addition to the PDGF- $\alpha$ and IGF-I receptors, are also targets for the EWS-WTl fusion protein. Instead of being repressed by WTl, these genes are upregulated in DSRCT tumours. ${ }^{36}$

Recently, WTl was reported to regulate connective tissue growth factor (CCN2) expression via novel elements in the promoter region of $\mathrm{CCN} 2 .^{7} \mathrm{CCN} 2$ is a TGF $\beta$ induced matricellular protein, produced by diverse cell types, which regulates many diverse cellular functions. ${ }^{8}$ Although there has been considerable focus on the role of CCN2 in the fibrosis of vital organs, its production by desmoplastic tumours has received relatively little attention. Given its matrigenic properties and transcriptional regulation by WTl, we analysed CCN2 expression in DSRCT.

\section{MATERIALS AND METHODS}

Archival, formalin fixed, paraffin wax embedded or frozen tissues from three cases of DSRCT were obtained with the approval of the institutional review board of the Children's Research Institute (Columbus, $\mathrm{OH}$ ) from the National Cancer Institute Cooperative Human Tissue Network. Other investigators may have received specimens from the same subjects. Total RNA was isolated from frozen tumour tissue and diagnostic reverse transcription polymerase chain reaction (RT-PCR) assays for DSRCT were performed using primers specific for the $\mathrm{t}(11 ; 22)$ translocation associated with DSRCT. ${ }^{9}$ The presence of the EWS-WT1 fusion product was verified by sequencing. Parallel tissue sections were stained with haematoxylin and eosin and examined for CCN2 mRNA and protein localisation by in situ hybridisation and immunohistochemistry, respectively. In situ hybridisation using digoxigenin labelled probes was performed as described previously, ${ }^{10}$ except that the sense and antisense probes corresponded to a 312 bp region encoding residues 245-349 of human CCN2. Slides were counterstained with nuclear fast green (Sigma-Aldrich Corp, St Louis, Missouri, USA). Immunohistochemistry was performed as described previously, using an affinity purified antihuman CCN2 peptide (residues 81-94), ${ }^{10}$ except that antigen retrieval was performed with antigen retrieval Citra solution (BioGenex Inc, San Ramon, California, USA). Slides were counterstained with haematoxylin and mounted.

\footnotetext{
Abbreviations: CCN2, connective tissue growth factor; DSRCT, desmoplastic small round cell tumour; EWS, Ewing sarcoma; IGF, insulin-like growth factor; PDGF, platelet derived growth factor; TGF $\beta$, transforming growth factor $\beta ;$ RT-PCR, reverse transcription polymerase chain reaction; WTI, Wilms's tumour protein
} 


\begin{tabular}{|c|c|c|c|c|c|c|}
\hline Patient & $\begin{array}{l}\text { Age at diagnosis } \\
\text { (years) }\end{array}$ & Site & Status & Histological subtyping & $\begin{array}{l}t(11 ; 22) \\
(p 13 ; q 12)\end{array}$ & $\begin{array}{l}\text { CCN2 } \\
\text { expression }\end{array}$ \\
\hline 1 & 15 & Lymph node & Dead & $\begin{array}{l}\text { Positive for vimentin, desmin, NSE, and } \\
\text { keratin }\end{array}$ & Negative & Negative \\
\hline 2 & 10.5 & Abdomen & Dead & $\begin{array}{l}\text { Positive for desmin and keratin } \\
\text { Negative for NSE and actin }\end{array}$ & Positive & Positive \\
\hline 3 & 15 & Peritoneum, omentum & Alive, NED & $\begin{array}{l}\text { Positive for desmin } \\
\text { Negative for CD } 45, \text { CD99, and actin }\end{array}$ & Positive & Positive \\
\hline
\end{tabular}

\section{RESULTS}

Based on diagnostic RT-PCR and sequencing, two of the three tumours were positive for the EWS-WTl fusion. Table l summarises the presence of this translocation, together with the clinical features and CCN2 expression profile of each tumour. Interestingly, the EWS-WTI negative tumour was also negative for CCN2 expression, whereas the two tumours that harboured the characteristic WTl translocation were positive for CCN2 mRNA expression, as shown by hybridisation to the CCN2 antisense probe but not to the CCN2 sense probe (fig 1A, B). The pattern of CCN2 mRNA distribution was very similar to that of the CCN2 protein, which was readily detected by anti-CCN2 IgG but not by non-immune IgG (fig $1 \mathrm{C}, \mathrm{D}$ ). CCN2 mRNA and protein expression were localised to the tumour cells (fig 1B, D; fig 2A), fibroblasts within the stromal compartment (fig 1B, D; fig 2B, E), and endothelial cells of the capillaries and arterioles (fig 2C, D, F). Haematoxylin and eosin staining confirmed the presence of characteristic islands of rounded, undifferentiated tumour cells within a collagen rich stromal matrix (fig $1 \mathrm{E}$ ).

\section{DISCUSSION}

Our study showed that DSRCT expresses CCN2 in both the tumour cells and supporting stromal fibroblasts and vascular endothelial cells, suggesting that CCN2 is involved in autocrine and paracrine pathways of action. Interestingly, the one DSRCT specimen that did not stain positively for CCN2 expression also did not have the typical EWS-WT1 translocation. Thus, our data suggest that CCN2 expression is associated with the EWS-WT1 fusion, which occurs in DSRCTs with a frequency of $\sim 95 \% .{ }^{11}$ Alternatively, it is possible that the EWS-WT1 negative tumour was incorrectly identified as DSRCT, although this would be inconsistent with other pathological indicators at the time of initial diagnosis (for the archival tissue in question, RT-PCR was performed several years after and independently of diagnosis).

Studies of other tumour types have shown considerable variability in the cellular localisation of CCN2. For example, glioblastomas, infantile myofibromatosis, malignant fibrohistiocytic tumours, and malignant haemangiopericytomas have moderate to intense CCN2 staining in the tumour cells, with mild to moderate CCN2 expression in the surrounding vascular endothelial cells. ${ }^{12}{ }^{13}$ In contrast, CCN2 is not expressed in the tumour cells of angiofibromas, squamous cell carcinomas associated with lung cancer, or mammary ductal carcinomas, yet it is present at high concentrations in the surrounding endothelial cells and stromal fibroblasts. ${ }^{12} 1415$ In desmoplastic tumours of the oesophagus and pancreas, $\mathrm{CCN} 2$ is expressed more prominently by stromal fibroblasts than by the tumour cells themselves. ${ }^{16}{ }^{17}$

"Our data suggest that, in desmoplastic small round cell tumour, the inhibitory control of CCN2 gene expression by WT1 may be overcome by the pathological fusion of EWS1 to WT1, leading to localised CCN2 overexpression and the concomitant formation of a desmoplastic stroma"
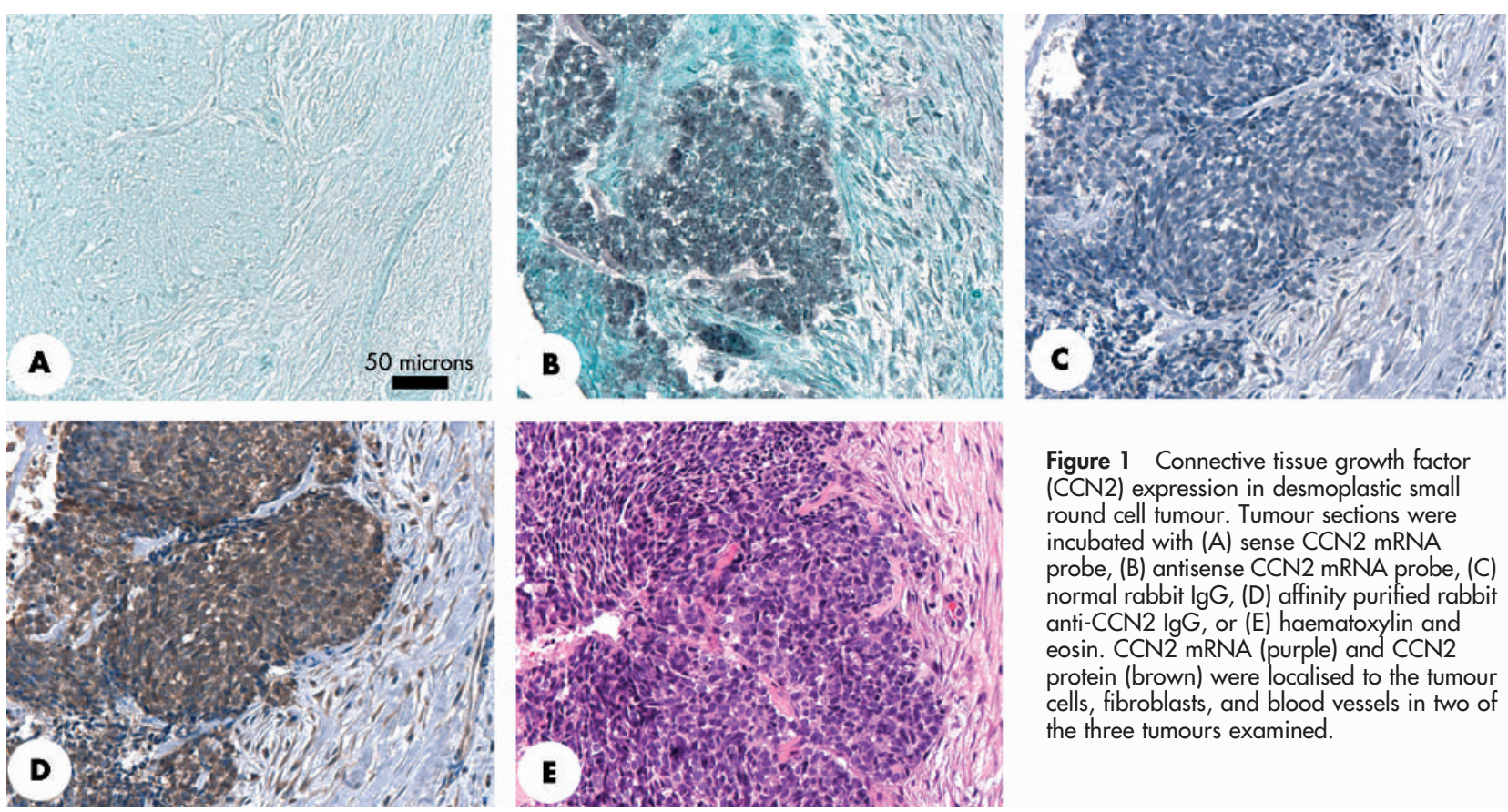

Figure 1 Connective tissue growth factor (CCN2) expression in desmoplastic small round cell tumour. Tumour sections were incubated with $(A)$ sense CCN2 mRNA probe, (B) antisense CCN2 mRNA probe, (C) normal rabbit lgG, (D) affinity purified rabbit anti-CCN2 lgG, or (E) haematoxylin and eosin. CCN2 mRNA (purple) and CCN2 protein (brown) were localised to the tumour cells, fibroblasts, and blood vessels in two of the three tumours examined. 

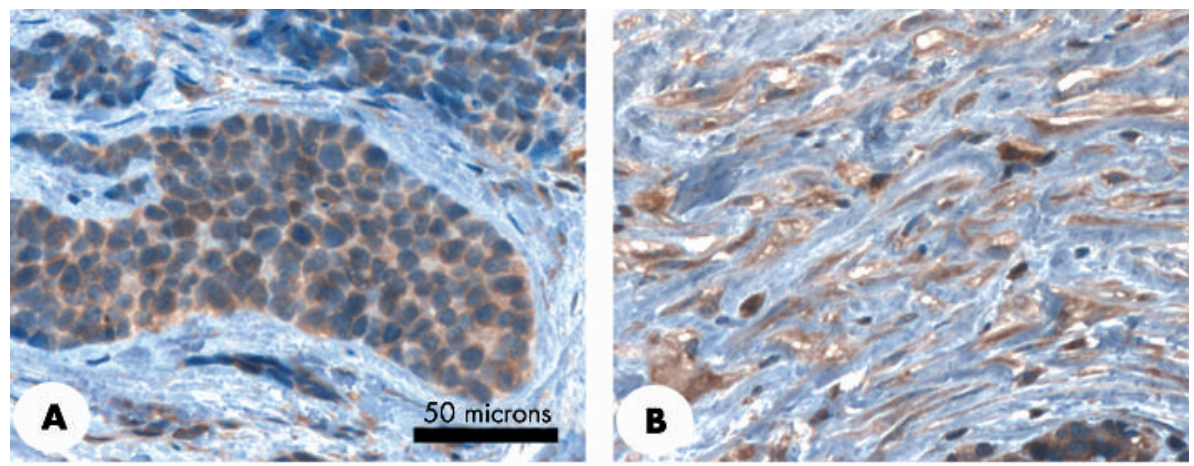

Figure 2 Cellular localization of connective tissue growth factor (CCN2) protein in desmoplastic small round cell tumour. Tumour sections were treated with anti-CCN2 lgG. CCN2 was detected in (A) tumour cells, (B) fibroblasts, (C) capillary endothelial cells, and (D) arteriolar endothelial cells. CCN2 mRNA was detected in (E) fibroblasts and (F) arteriolar endothelial cells. The location of blood vessels was confirmed by staining for factor VIII (not shown).
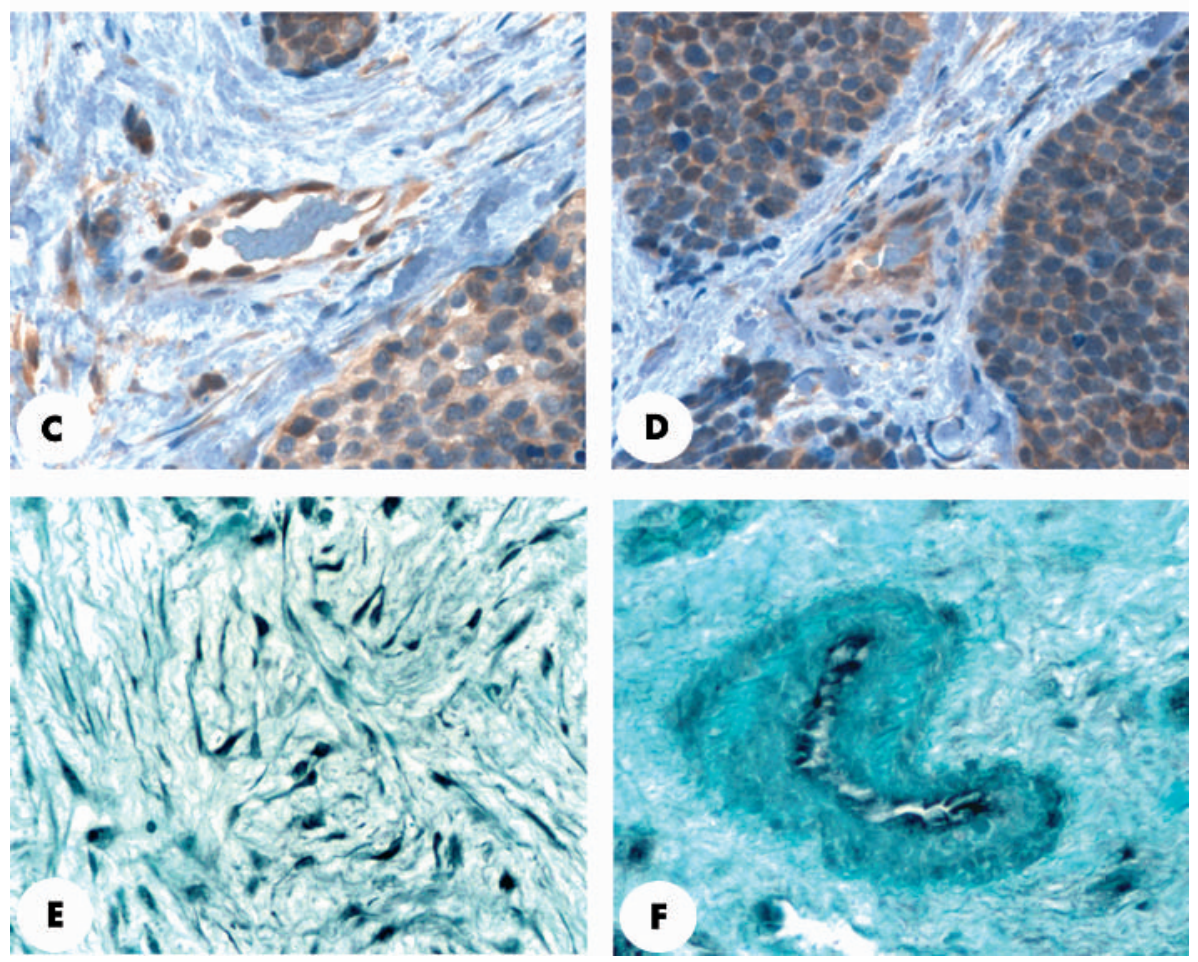

The production of CCN2 by several cell types in DSRCT is consistent with its participation in autocrine and paracrine pathways that are involved in processes such as tumour growth, angiogenesis, and desmoplasia. Although the matrigenic, fibrogenic, and angiogenic properties of CCN2 are well documented, ${ }^{8}$ its precise roles in tumour cell function have yet to be clarified. CCN2 overexpression is correlated with increased survival in oesophageal squamous cell carcinoma,

\section{Take home messages}

- In desmoplastic small round cell tumour (DSRCT), connective tissue growth factor (CCN2) mRNA and protein were expressed in the tumour cells themselves, in addition to stromal fibroblasts and vascular endothelial cells

- CCN2 is produced in high amounts by several cell types in DSRCT, and it may play a role in the autocrine and paracrine regulation of tumour cell growth, matrigenesis, and angiogenesis

- CCN2 or other CCN proteins may be useful targets for developing novel therapeutic approaches for combating DSRCT oral squamous cell carcinoma, and chondrosarcoma, but negatively correlated with survival in oesophageal adenocarcinoma. ${ }^{16}{ }^{18} 19$ In addition, increased expression of CCN2 was associated with a loss of tumorigenicity in human embryonal carcinoma cells, and CCN2 expression was decreased in Wilms's tumour. ${ }^{70}$ Increased concentrations of CCN2 are present in pancreatic tumours and are associated with tumorigenicity in astrocytomas, whereas the ability of breast cancer cells to metastasise is associated with the expression of both CCN2 and its close relative, CCN1. ${ }^{17} 21-23$

WT1 plays important roles in development, tumorigenesis, RNA splicing, DNA replication, and apoptosis, but is best characterised as a tumour suppressing transcription factor. ${ }^{4}$ Novel binding sites in the CCN2 promoter are used by WT1 to suppress CCN2 expression, both in its endogenous location and in a reporter construct. ${ }^{7}$ The EWS-WTl fusion is able to recognise and activate the same set of target genes that are usually negatively regulated by WTl. Taken together, our data suggest that, in DSRCT, the inhibitory control of CCN2 gene expression by WTI may be overcome by the pathological fusion of EWS1 to WT1, leading to localised CCN2 overexpression and the concomitant formation of a desmoplastic stroma. Although this mechanism has yet to be confirmed, the related family member, CCN3, was identified as a potential target of WT1, ${ }^{24}$ and was highly expressed in a case of DSRCT. ${ }^{25}$ Thus, CCN2 or other CCN proteins may be useful 
targets for developing novel therapeutic approaches for combating DSRCT.

\section{ACKNOWLEDGEMENTS}

This work was supported by NIH grant AAl2817 awarded to DRB. CHTN received funding from the National Cancer Institute. We are grateful for assistance from Dr J Gastier-Foster (Molecular Genetics Laboratory, Children's Hospital, Columbus, OH, USA) and J M Smith (CHTN Pediatric Division, Children's Research Institute, Columbus, $\mathrm{OH}, \mathrm{USA})$.

\section{Authors' affiliations}

A W Rachfal, D R Brigstock, Center for Cell and Vascular Biology, Children's Research Institute, Columbus Ohio 43205, USA

M H Luquette, Department of Pathology, Children's Hospital, Columbus $\mathrm{OH} 43205$, USA

Correspondence to: Dr D R Brigstock, Center for Cell and Vascular Biology, Children's Research Institute, Room NA 2022, 700 Children's Drive, Columbus Ohio 43205, USA; brigstod@pediatrics.ohio-state.edu

Accepted for publication 3 November 2003

\section{REFERENCES}

1 Leuschner I, Radig K, Harms D. Desmoplastic small round cell tumor. Semin Diagn Pathol 1996;13:204-12.

2 Rodriguez E, Sreekantaiah C, Gerald W, et al. A recurring translocation, $t(11 ; 22)(p 13 ; q 11.2)$, characterizes intra-abdominal desmoplastic small round-cell tumors. Cancer Genet Cytogenet 1993;69:17-21.

3 Froberg K, Brown RE, Gaylord H, et al. Intra-abdominal desmoplastic small round cell tumor: immunohistochemical evidence for up-regulation of autocrine and paracrine growth factors. Ann Clin Lab Sci 1999;29:78-85.

4 Scharnhorst V, van der Eb AJ, Jochemsen AG. WT1 proteins: functions in growth and differentiation. Gene 2001;273:141-61.

5 Lee TH, Moffett P, Pelletier J. The Wilms' tumor suppressor gene (wt1) product represses different functional classes of transcriptional activation domains. Nucleic Acids Res 1999;27:2889-97.

6 Karnieli E, Werner H, Rauscher FJ 3rd, et al. he IGF-I receptor gene promoter is a molecular target for the Ewing's sarcoma-Wilms' tumor 1 fusion protein. J Biol Chem 1996;271:19304-9.

7 Stanhope-Baker P, Williams BR. Identification of connective tissue growth factor as a target of WT1 transcriptional regulation. J Biol Chem 2000;275:38139-50.
8 Brigstock DR. The connective tissue growth factor/cysteine-rich 61/ nephroblastoma overexpressed (CCN) family. Endocr Rev 1999;20:189-206.

9 de Alava E, Ladanyi M, Rosai J, et al. Detection of chimeric transcripts in desmoplastic small round cell tumor and related developmental tumors by reverse transcriptase polymerase chain reaction. A specific diagnostic assay. Am J Pathol 1995; 147:1584-91.

10 Moussad EE, Rageh MA, Wilson AK, et al. Temporal and spatial expression of connective tissue growth factor (CCN2; CTGF) and transforming growth factor beta type 1 (TGF-betal) at the utero-placental interface during early pregnancy in the pig. Mol Pathol 2002;55:186-92.

11 Lae ME, Roche PC, Jin L, et al. Desmoplastic small round cell tumor: a clinicopathologic, immunohistochemical, and molecular study of 32 tumors. Am J Surg Pathol 2002;26:823-35.

12 Kasaragod AB, Lucia MS, Cabirac G, et al. Connective tissue growth factor expression in pediatric myofibroblastic tumors. Pediatr Dev Pathol $2001 ; 3: 37-45$

13 Pan LH, Beppu T, Kurose A, et al. Neoplastic cells and proliferating endothelial cells express connective tissue growth factor (CTGF) in glioblastoma. Neurol Res 2002;24:677-83.

14 Querfeld C, Sollberg S, Huerkamp C, et al. Pseudoscleroderma associated with lung cancer: correlation of collagen type I and connective tissue growth factor gene expression. Br J Dermatol 2000;142:1228-33.

15 Frazier KS, Grotendorst GR. Expression of connective tissue growth factor mRNA in the fibrous stroma of mammary tumors. Int J Biochem Cell Biol 1997;29:153-61.

16 Koliopanos A, Friess H, di Mola FF, et al. Connective tissue growth factor gene expression alters tumor progression in esophageal cancer. World J Surg 2002;26:420-7.

17 Wenger C, Ellenrieder V, Alber B, et al. Expression and differential regulation of connective tissue growth factor in pancreatic cancer cells. Oncogene 1999; 18: 1073-80.

18 Moritani NH, Kubota S, Nishida T, et al. Suppressive effect of overexpressed connective tissue growth factor on tumor cell growth in a human oral squamous cell carcinoma-derived cell line. Cancer Lett 2003;192:205-14.

19 Shakunaga T, Ozaki T, Ohara N, et al. Expression of connective tissue growth factor in cartilaginous tumors. Cancer 2000;89:1466-73.

20 Freemantle SJ, Kerley JS, Olsen SL, et al. Developmentally-related candidate retinoic acid target genes regulated early during neuronal differentiation of human embryonal carcinoma. Oncogene 2002;21:2880-9.

21 Kang Y, Siegel PM, Shu W, et al. A multigenic program mediating breast cancer metastasis to bone. Cancer Cell 2003:3:537-49.

22 Menendez JA, Mehmi I, Griggs DW, et al. The angiogenic factor CYR61 in breast cancer: molecular pathology and therapeutic perspectives. Endocr Relat Cancer 2003;10:139-50.

23 Rubenstein J, Shen A, Haqq C, et al. Connective tissue growth factor is expressed in malignant astrocytic tumors and is involved in cell-cycle regulation. Mol Pathol 2003;56:72.

24 Martinerie C, Chevalier G, Rauscher FJ 3rd, et al. Regulation of nov by WT1: a potential role for nov in nephrogenesis. Oncogene 1996;12:1479-92.

25 Chevalier G, Yeger H, Martinerie C, et al. NovH: differential expression in developing kidney and Wilm's tumors. Am J Pathol 1998;152:1563-75. 